\title{
Ibuprofen-Loaded CTS/nHA/nBG Scaffolds for the Applications of Hard Tissue Engineering
}

\author{
Pawan Kumar ${ }^{1 *}$, Brijnandan S. Dehiya ${ }^{1}$ and Anil Sindhu ${ }^{2}$ \\ ${ }^{1}$ Department of Materials Science and Nanotechnology, Deenbandhu Chhotu Ram University of Science and \\ Technology, Murthal 131039, India; ${ }^{2}$ Department of Biotechnology, Deenbandhu Chhotu Ram \\ University of Science and Technology, Murthal 131039, India
}

Received 26 May 2018; revised 28 July 2018; accepted 29 July 2018

\begin{abstract}
Background: This study addressed the development of biodegradable and biocompatible scaffolds with enhanced biomechanical characteristics. The biocompatibility and the cationic nature of chitosan (CTS) make it more effective as a bone grafting material. Methods: The hydroxyapatite nanoparticles (nHA) were synthesized by hydrothermal method, and bioglass ( $\mathrm{nBG})\left(50 \% \mathrm{SiO}_{2}-45 \% \mathrm{CaO}-5 \% \mathrm{P}_{2} \mathrm{O}_{5}\right)$ was synthesized using sol-gel method. The ibuprofen-loaded CTS/nHA and CTS/nBG scaffolds were fabricated by using freeze-drying method. Results: Transmission electron microscopy image of $\mathrm{nHA}$ and $\mathrm{nBG}$ revealed the particles of less than $200 \mathrm{~nm}$. The scanning electron microscopy (SEM) images of CTS/nHA and CTS/nBG scaffolds showed pore sizes ranging from 84-190 $\mu \mathrm{m}$. The physiochemical characteristics of synthesized ceramic nanoparticles and scaffolds analyzed by XRD were confirmed by ICDD 9-432. The porosity of scaffolds was measured by using SEM, Brunauer-Emmett-Teller method, and Archimedes' principle. The open porosities of CTS/nBG and CTS/nHA samples were $29 \%$ and $31 \%$, respectively. The compressive strength of scaffolds was evaluated by stress vs. strain curve. The CTS/nHA scaffold revealed $4 \%$ more water retention capacity than CTS/nBG scaffold. In the presence of lysozyme, CTS/nBG scaffold degraded $32.8 \%$, while CTS/nHA degraded $26.1 \%$ in PBS solution at $\mathrm{pH}$ 7.4. The density of all scaffolds was found $\left(1.9824 \mathrm{~g} / \mathrm{cm}^{-3}\right.$ and $\left.1.9338 \mathrm{~g} / \mathrm{cm}^{-3}\right)$ to be nearly similar to that of the dry bone $\left(0.8-1.2 \mathrm{~g} / \mathrm{cm}^{-3}\right)$. Fibroblast cells multiplied two times in the sample medium of CTS/nBG after 14 days. After $72 \mathrm{~h}, \mathrm{CTS} / \mathrm{nBG}$ and CTS/nHA scaffolds demonstrated $52 \%$ and $46 \%$ drug release, respectively. Conclusion: Based on our findings, ibuprofen-loaded scaffolds could be an effective drug delivery system for tissue engineering applications. DOI: 10.29252/ibj.23.3.190
\end{abstract}

Keywords: Chitosan, Fibroblast, Ibuprofen, Nanoparticles

Corresponding Author: Pawan Kumar

Department of Materials Science and Nanotechnology, Deenbandhu Chhotu Ram University of Science and Technology, Haryana, India;

Tel.: (+91-946) 7252002; E-mail: pawankamiya@yahoo.in

\section{INTRODUCTION}

$\mathrm{T}$ rauma, injury, infections, and degenerative diseases can lead to bone loss as a health threatening problem. Tissue Engineering, as a promising technology, can provide new treatment opportunities with eliminating issues like donor site morbidity, less availability of tissue donor, immunogenicity, and infection-causing microbes transfer. The pore sizes of human bones, including long, short, flat, and irregular are 100-300 $\mu \mathrm{m}^{[1]}$. Nutrients can actively diffuse from bone-blood supply to the bone tissue via $150-200 \mu \mathrm{m}$ pores. Bone tissue also contains mineralized (type-1 collagen) and nonmineralized organic components $(4 \mathrm{~nm}$ thick carbonated apatite) as a part of the bone extracellular matrix $(\mathrm{ECM})^{[2,3]}$. In bone tissue engineering, artificial bone graft materials such as inorganic materials (hydroxyapatite nanoparticles [nHA], bioactive glass, etc.) and biodegradable polymers [poly(lactic acid), poly(lactic-co-glycolic) acid, gelatin, and soon] have been used as substitutes. However, none of the above materials can meet all the demands because of low mechanical properties ${ }^{[4,5]}$. Engineered biomaterials 
might cause chronic post-surgical paint that is attributed due to changes in the central nervous system arising because of nerve injury/inflammation. To reduce pain and excessive inflammation, oral administration of nonsteroidal anti-inflammatory drugs is very common due to their lesser side effects compared to opioids ${ }^{[6]}$. However, the large dose of ibuprofen may produce adverse effects such as gastric ulcer and renal failure. This situation justifies the significance of ideal drug delivery in tissue engineering. Anti-inflammatory drug delivery supports new tissue generation without pain and inflammatory reactions. Tissue engineering also includes the injection of specific cells in an injured tissue, delivery of different biomolecules such as polysaccharides, growth factors, and peptides to a selected tissue, which support growth and regeneration of injured tissues ${ }^{[7]}$. Chitosan (CTS) is a derivative of naturally occuring polymer chitin, used in tissue restoration ${ }^{[8]}$. Positive charged CTS can bind to negatively charged molecules (glycosaminoglycan [GAG]) and proteoglycans ${ }^{[9]}$. GAG is the major component of the ECM of bone and cartilage, and polysaccharide backbone of CTS is structurally similar to $\mathrm{GAG}^{[10]}$. GAG is also the main component of ECMs in tissue and causes cell adhesion and proliferation due to its high biocompatibility and non-immunogenic properties. The CTS can be used to form different porous three dimensional structures ${ }^{[11]}$, gels $^{[12]}$, thin films ${ }^{[13]}$, membranes ${ }^{[14]}$, and fibers ${ }^{[15]}$, which all are very promising for bone tissue regrowth. However, CTS has some downsides, such as lack of sufficient mechanical strength, rapid degradation, and lacking of bioactive cell signaling molecules, which are vital for the regeneration of bone tissue ${ }^{[16]}$.

The nHA showing good phase and dimensional stability. It will significantly improve composite density, smoothness, and fracture toughness. Due to the inert property, nHA have medical and health applications; they are present in the inorganic part of bones and human teeth as well as in cuttlefish shells and corals. The equivalent crystal size identified in chemically synthesized HA and natural HA can be seen in hard tissues. In our previous investigation on HA, we have observed the standard stoichiometric ratio of $1.667(\mathrm{Ca} / \mathrm{P})^{[17]}$. HA boosts up the formation of apatitelike structure between HA and tissues by supporting chemical interactions ${ }^{[18,19]}$.

Bioglass is a bioactive material that induces biological activity by promoting some surface reactions. It supports the formation of apatite-like structure between bioglass and hard tissues when implanting in the human body. The formation of apatite layer confirmed the effective biological interaction and fixation of hard tissue with the material surface $^{[20]}$. The apatite layer can be generated artificially on the surface of bioglass when the material is placed in the simulated body fluid (SBF) for some days. The main goal of this study was to fabricate ibuprofen-loaded CTS/nHA and CTS/nBG (bioglass nanoparticles) scaffolds with improved mechanical and biological properties. Loading of these two new compositions (CTS/nHA and CTS/nBG) by ibuprofen may help in the restoration of tissue defects.

\section{MATERIALS AND METHODS}

Acetic acid (SUK-320099), sodium hydroxide pellets (SUK-567530), low molecular weight CTS (75-85\% deacetylated, SUK-448869), glutaraldehyde (SUKG5882), calcium nitrate tetrahydrate (SUK-C1396), phosphorus pentoxide (SUK-431419), diammonium hydrogen phosphate (SUK-1012070500), tetraethyl orthosilicate (SUK-131903) and ibuprofen salt (SUKI1892) were procured from Sigma Aldrich (USA). Lysozyme (code 45822) was purchased from Sisco Research Laboratories Pvt. Ltd (India).

\section{Synthesis of hydroxyapatite and bioglass nanoparticles}

The stepwise hydrothermal synthesis of nHA is shown in Figure 1. At first, $1 \mathrm{M}$ solution of both calcium nitrate tetrahydrate $(11.807 \mathrm{~g})$ and diammonium hydrogen phosphate (6.603 g) was prepared using $50 \mathrm{~mL}$ distilled water and subsequently diluted further to create $0.10 \mathrm{M}$ solutions. By the dropwise addition of the calcium nitrate tetra hydrate solution $(50 \mathrm{~mL})$ to the di-ammonium hydrogen phosphate solution, precipitate was formed with continuous stirring to get a $1.67(\mathrm{Ca} / \mathrm{P}$ ratio $)$ in the miscellaneous solution ${ }^{[21]}$. The white colored crystalline powder was collected after drying at $80{ }^{\circ} \mathrm{C}$ and $400{ }^{\circ} \mathrm{C}$.

The sol-gel method was selected for the synthesis of nBG. For the synthesis of the novel composition of bioglass $\left(50 \% \quad \mathrm{SiO}_{2}-45 \% \mathrm{CaO}-5 \% \quad \mathrm{P}_{2} \mathrm{O}_{5}\right), 8.108 \mathrm{~g}$ of tetraethyl orthosilicate was mixed with $100 \mathrm{ml}$ of ethanol and allowed continuous stirring for one hour. After that, $4.454 \mathrm{~g}$ of calcium nitrate tetrahydrate and $0.534 \mathrm{~g}$ of phosphorus pentoxide were dissolved in distilled water with 30 minutes stirring to get $100 \mathrm{ml}$ of mixture, which was added dropwise to tetraethyl orthosilicate solution until a homogenous mixture with pH 5 was obtained. Ammonia solution was used to maintain $\mathrm{pH}$ at 11 , and the solution was transferred to an incubator and kept for $72 \mathrm{~h}$ for aging in order to obtain the gel. The aged gel was placed in an oven at $100{ }^{\circ} \mathrm{C}$ for drying to eliminate ethanol ${ }^{[22,23]}$. The dried 


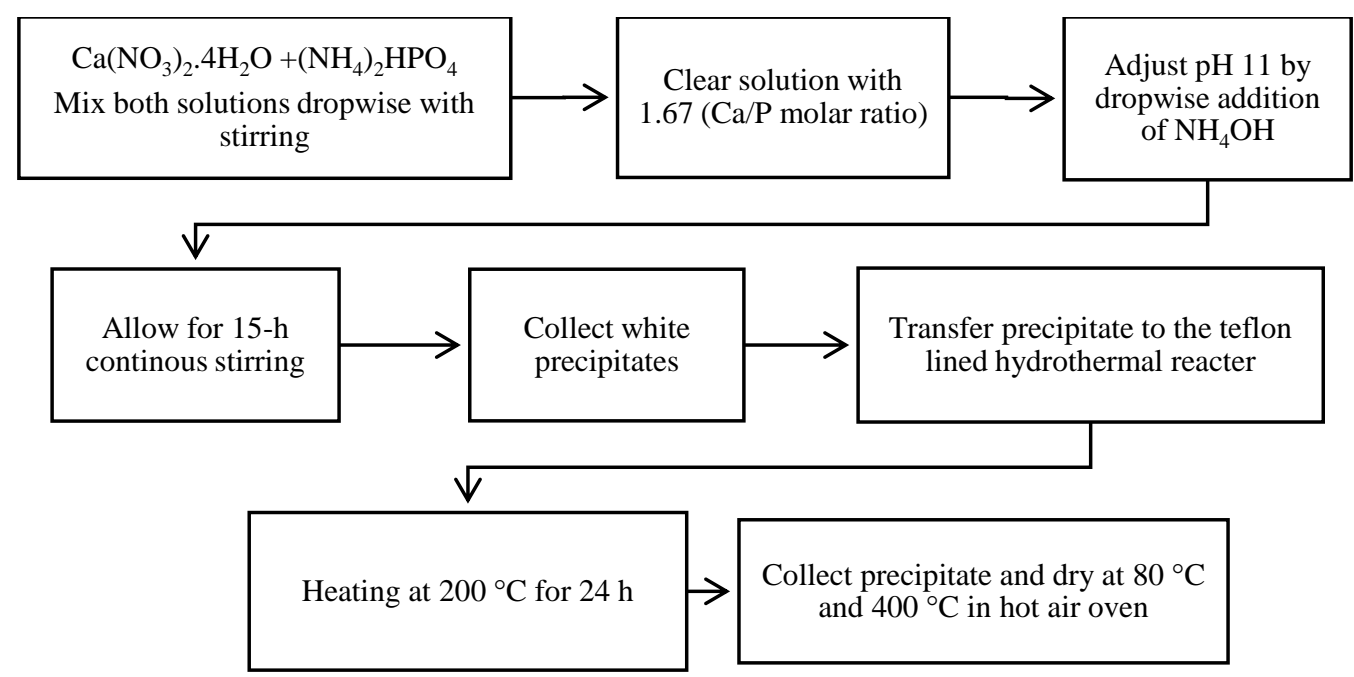

Fig. 1. Hydroxyapatite nanoparticles (nHA) synthesis using hydrothermal method.

gel was then heated at $700{ }^{\circ} \mathrm{C}$ for $24 \mathrm{~h}$ to stabilize the glass and also to eliminate residual nitrate ${ }^{[24]}$.

\section{Scaffolds synthesis}

Ibuprofen loaded- and unloaded-CTS/nHA and -CTS/nBG scaffolds were synthesized using freezedrying method. Acetic acid (1\% w/v) was mixed with $2 \%$ (w/v) CTS solution (75-85\% deacetylated). Glutaraldehyde $(0.25 \%)$ was incorporated in the mixture solution that helps to make cross-linking under agitation at room temperature for $15 \mathrm{~h}$. An appropriate amount of $\mathrm{nHA}$ and $\mathrm{nBG}$ was added to the mixture solution separately with continuous $15 \mathrm{~h}$ stirring for proper mixing. Then ibuprofen $(10 \% \mathrm{w} / \mathrm{w}$ of polymer) solution was added to the mixture solution separately ${ }^{[25,26]}$, and the homogeneous mixture of ibuprofen-loaded and -unloaded samples were distributed into Petri dishes. The dishes were placed within a deep freezer at $-80{ }^{\circ} \mathrm{C}$. The frozen sample was kept at lower temperature in a chamber where the ice was removed by sublimation and the unfrozen water by desorption in a secondary drying process ${ }^{[27]}$. The unwanted acetate was removed by using $10 \% \mathrm{NaOH}$ solution, followed by three times washing with distilled water. The lyophilizer was used for $48 \mathrm{~h}$ to lyophilize the frozen hydrogels. Sodium borohydride solution $(5 \%)$ and deionized water were used to block non-responded aldehyde group in the samples ${ }^{[8,28,29]}$. The scaffolds of ibuprofen-loaded-CTS/nBG and -CTS/nHA are shown in Figure 2.

\section{Standard calibration curve of ibuprofen}

The stock solution of ibuprofen was prepared by dissolving $20 \mathrm{mg}$ drug into $100 \mathrm{ml}$ phosphate buffer (pH 6.8), which was used to plot a standard curve of ibuprofen. The four different concentrations (0.1, $0.05,0.025$, and $0.0125 \mathrm{mg} / \mathrm{ml}$ ) were prepared from the stock solution. UV-visible spectrophotometer

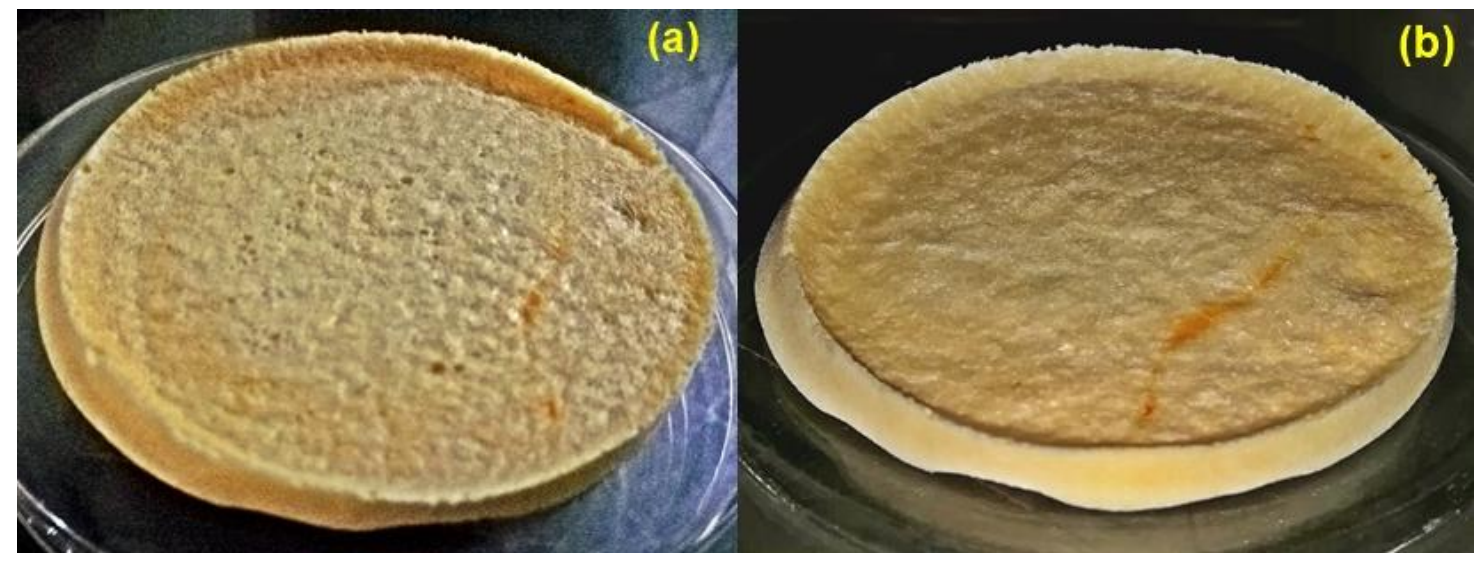

Fig. 2. Images of ibuprofen-loaded CTS/nBG (a) and CTS/nHA (b) scaffold. 


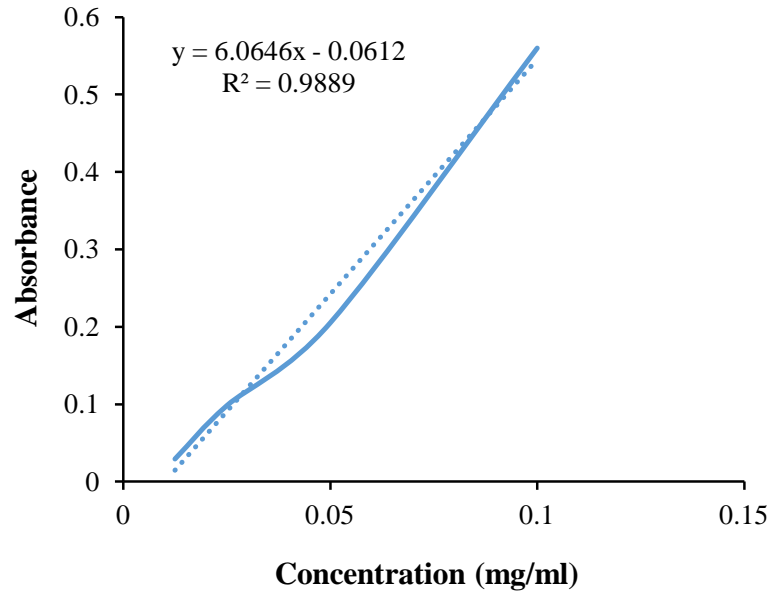

Fig. 3. Standard calibration curve of ibuprofen.

(Shimadzu, Japan) was used to analyze the absorbance of these dilutions. The standard curve was prepared by plotting different concentrations of ibuprofen against absorption as shown in Figure 3.

\section{Measurement of ibuprofen release}

The drug-loaded scaffolds were cut into small pieces of $25 \mathrm{mg}$ and placed into the PBS at $37^{\circ} \mathrm{C}$. The drug release from scaffolds was monitored after $24 \mathrm{~h}, 48 \mathrm{~h}$, and $72 \mathrm{~h}$ using UV/Vis spectroscopy at 220 and 218 $\mathrm{nm}$. The results of UV/Vis spectroscopy were calibrated with the calculated standard curve of ibuprofen $^{[25]}$ and are shown in Figure 4. The amount of ibuprofen release was estimated by equation 1 . Experiments were run in triplicates.

$$
Q=C_{n} V+V_{s} \sum_{i=1}^{n-1}
$$

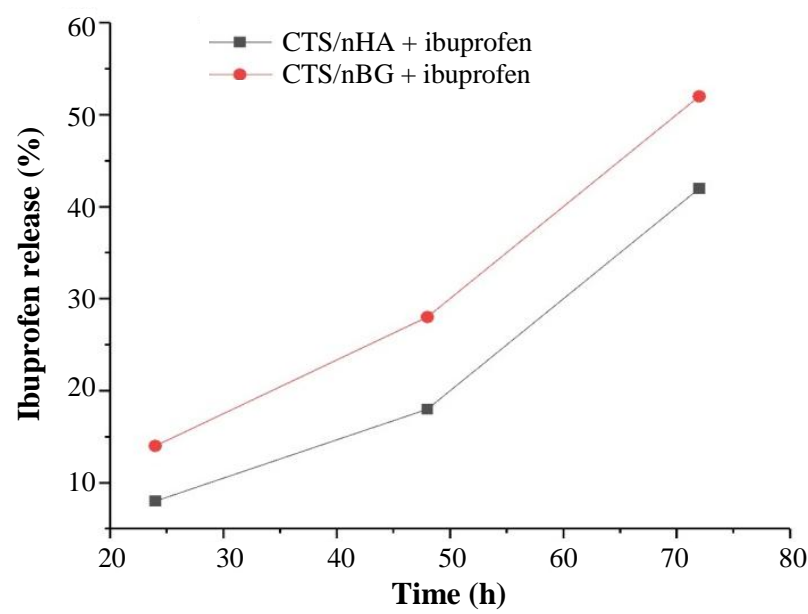

Fig. 4. Ibuprofen release with respect to time changes.
Where Q is the amount of ibuprofen released, $C_{n}$ is the concentration of samples, $\mathrm{V}$ is the volume of in vitro released solution, and $\mathrm{V}_{\mathrm{s}}$ is the sampling volume.

\section{Characterization \\ XRD analysis}

The samples of nanoparticles (nHA and $\mathrm{nBG}$ ) as well as ibuprofen-loaded and -unloaded scaffolds (CTS/nBG and CTS/nHA) were analyzed with XRD (Rigaku Ultima IV) with the scanning rate of $1^{\circ}$ per second over the range of $2 \theta$ angles from $15^{\circ}$ to $60^{\circ}$.

\section{Transmission electron microscopy (TEM)}

TEM produces high-resolution images by transmitting high-energy electron through the specimen. Structure, composition, and size of nanoparticles (nHA and $\mathrm{nBG}$ ) were analyzed by TEM (Hitachi H-7500, Japan);

\section{Scanning electron microcopy (SEM)}

The detailed surface information such as composition, topography, and porosity of samples were observed by scanning electron microscopy (SEM; JEOL, Japan). The surface and fracture section of the samples were coated with gold.

\section{Porosity}

The pore volume, micro-pore radius, and pore specific surface area of the sample were examined by BET (Quantachrome ${ }^{\circledR}$ Nova Station, USA). The small sized pieces of the scaffold were located in the sample tube, and the measurement conditions were set. Most of the results were concentration and viscosity dependent.

\section{Mechanical properties}

The sample size of $4 \times 4 \times 4 \mathrm{~mm}^{3}$ was cut from the scaffolds for the compressive strength measurement. The test piece (scaffold) is compressed between the platens of a machine by a gradually applied load. The quantitative results are presented as the mean \pm standard error. The stress vs. strain graph was used to explain the compressive strength of the scaffolds (Fig. 5 and Table 1).

\section{Density and open porosity}

The open porosity of sample scaffold was calculated by Archimedes' principle. The small pieces of scaffold were employed for the measurement. The sample was dipped into a water-containing beaker and kept inside the desiccator for 30 minutes. The suspended weight and soaked weight of sample scaffold were taken for further calculations. The equations 2 and 3 used to measure the bulk density and porosity are given below $^{[30]}$ : 


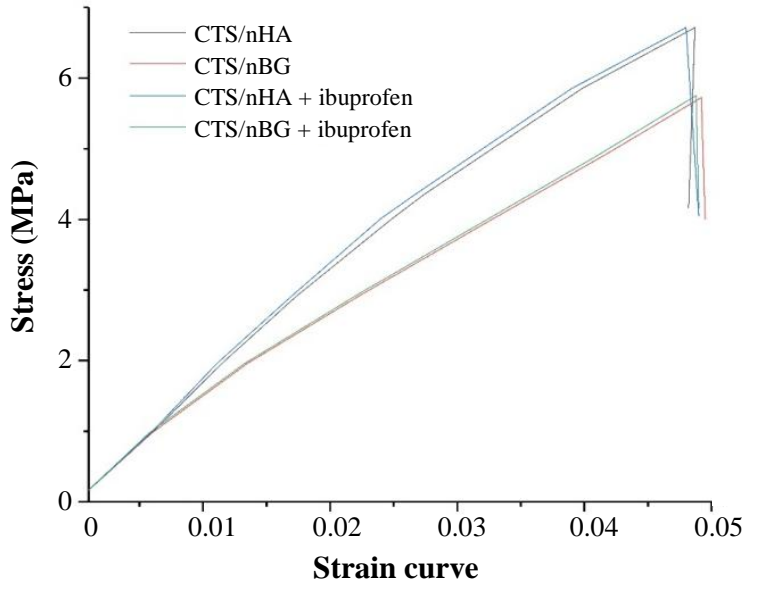

Fig. 5. Stress vs. strain curve of ibuprofen-loaded and -unloaded scaffolds.

Bulk density $\left(\rho_{b}\right)=\frac{W_{1} \times \text { Density of Water }\left(\rho_{w}\right)}{W_{3}-W_{2}}$

Open porosity $(\%)=\frac{W_{3}-W_{1}}{W_{3}-W_{2}} \times 100$

Where $\mathrm{W}_{1}$ is the weight of sample in air, $\mathrm{W}_{2}$ is weight of sample in distilled water, and $\mathrm{W}_{3}$ is wet mass of sample after removal from distilled water.

\section{Swelling behavior and degradation}

PBS solution was used to check the swelling or water retention capability of the sample scaffold. The swelling capacity depends on the porosity of the sample and nature of materials. The swelling capacity of the sample was calculated by the equation $4^{[28,31]}$. The comparative analysis of swelling behavior of scaffolds is shown in Figure 6.

$$
\text { Water retention }(\%)=\frac{W_{w}-W_{d}}{W_{d}} \times 100
$$

Where $\mathrm{W}_{\mathrm{d}}$ is initial weight, and $\mathrm{W}_{\mathrm{w}}$ is the weight of the sample after swelling.

The measurement of in vitro weight degradation of the scaffolds was required to estimate the bioavailability of materials. The pieces of the sample were incubated in the PBS solution ( $\mathrm{pH}$ 7.4) containing $1 \times 10^{4} \mathrm{U} / \mathrm{ml}$ of lysozyme at room temperature for 14 days. After the interval of 7 and 14 days, degradation of the sample was recorded by using equation $5^{[28]}$. The in vitro weight loss comparison between scaffolds is shown in Figure 7.

$$
\text { Weight degraded }(\%)=\frac{W_{f}-W_{0}}{W_{0}} \times 100
$$

Where $W_{0}$ is initial weight and $W_{f}$ is the final weight after degradation sample.

\section{Mineralization behavior}

Every material has distinct bioactivity or the ability to make bonding with body tissues. The bioactivity of any material depends upon various factors, including physiochemical behavior and morphological characteristics of materials. The SBF was used to measure the mineralization behavior of ibuprofenloaded CTS/nHA and CTS/nBG scaffolds because SBF consists of nearly the same concentration of inorganic constituents in blood plasma.

\section{Cell studies}

To check the cytotoxicity of scaffolds, fibroblast cell lines were maintained in the cell culture facility in minimum essential medium (MEM) with $10 \%$ FBS and $100 \mathrm{U} / \mathrm{ml}$ penicillin-streptomycin. Before cell seeding, all the sample scaffolds were sterilized and placed in an incubator with cell culture for two hours with $5 \%$ $\mathrm{CO}_{2}$ and $85 \%$ humidity.

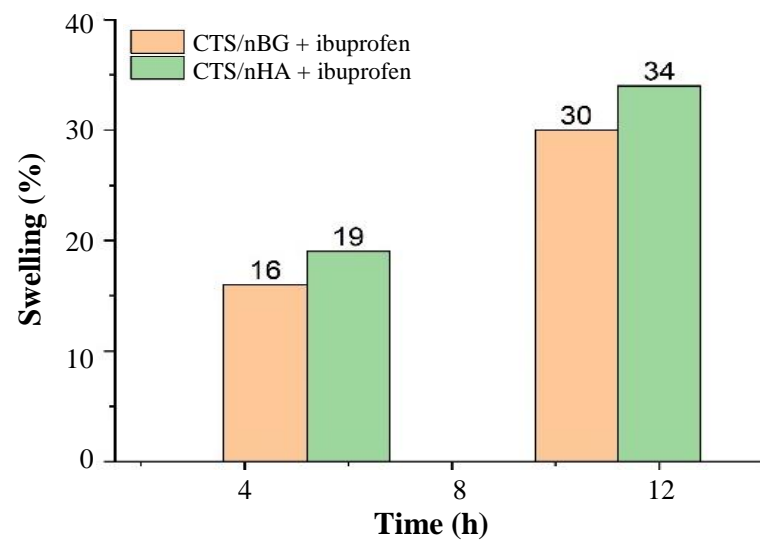

Fig. 6. Swelling behavior of scaffolds in PBS.

Table 1. Elastic modulus and compressive strength of scaffolds

\begin{tabular}{lcccc}
\hline \multirow{2}{*}{ Sample } & CTS/nHA & CTS/nHA + ibuprofen & CTS/nBG & \multicolumn{2}{c}{ CTS/nBG + ibuprofen } \\
& $(\mathbf{M P a})$ & $(\mathbf{M P a})$ & $(\mathbf{M P a})$ & \pm 118.58 \\
\hline Elastic modulus & \pm 136.5 & \pm 138.52 & \pm 117.55 & \pm 5.74 \\
Compressive strength & \pm 6.69 & \pm 6.67 & \pm 5.76 & \pm \\
\hline
\end{tabular}




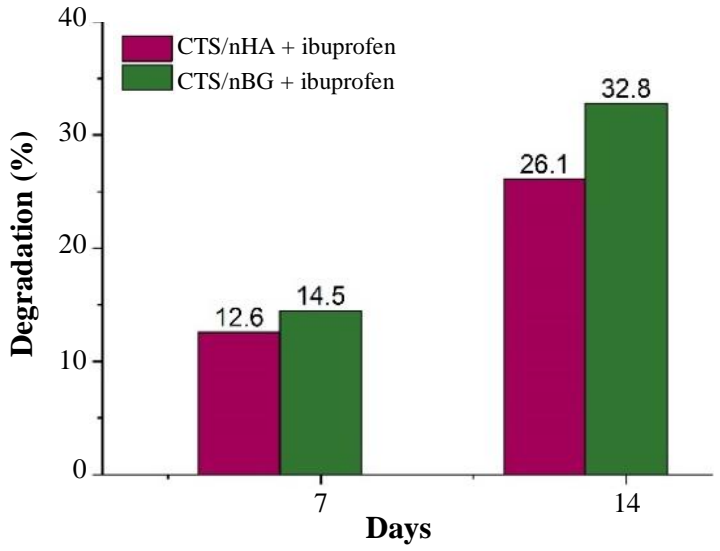

Fig. 7. In vitro degradation of scaffolds biodegradation.

The detached cells $\left(1 \times 10^{5}\right.$ cells $\left./ 100 \mu \mathrm{l}\right)$ were seeded dropwise on the surface of scaffolds for the investigation of cytocompatibility. The cell-seeded scaffolds were placed in a humidified incubator at 37 ${ }^{\circ} \mathrm{C}$ for $4 \mathrm{~h}$ for the cell attachment.

\section{RESULTS AND DISCUSSION}

In this study, white colored hydroxyapatite and nBG were synthesized by hydrothermal and sol-gel method, respectively. Ibuprofen-loaded and -unloaded CTS/nHA and CTS/nBG scaffolds were successfully fabricated by freeze-drying method. The XRD pattern confirmed the fabrication of nanoparticles and scaffolds calibrated with ICDD 9-432. The sharp peaks in spectra verified the crystalline nature of HA, and broad peaks approved the amorphous nature of bioglass. The phase changes in XRD spectrum were observed due to the addition of CTS and ibuprofen as shown in Figure 8. Ibuprofen binds CTS through electrostatic and via hydrophobic interactions, as well as hydrogen bonding ${ }^{[31]}$. The ammonium groups of CTS (low molecular weight) were involved in ionic interaction with the carboxylate anion of ibuprofen ${ }^{[32]}$. Bone is composed of $43 \%$ minerals (mainly HA, 69$80 \%$ of mineral content of bone), $28-30 \%$ collagen, 5$7 \%$ bone cells, and $10-20 \%$ water $^{[27]}$. The complex structural composition of bone needs a compositebased substitute/implant for bone tissue engineering. The CTS/nHA scaffold consists of nHA $(\mathrm{Ca} / \mathrm{P})$ as well as the polymeric phase that can easily mimic the ECM of bone. In CTS/nBG scaffold, nano-silica supports in vitro and in vivo cell proliferation ${ }^{[10]}$ without toxicity and inflammation ${ }^{[33]}$. The in vitro and in vivo tissue ingrowth has been shown in numerous studies ${ }^{[34-37]}$. CTS can be easily degraded by lysozyme ${ }^{[38]}$ and possesses immunological activity, by activating macrophages, which prevent infections ${ }^{[39,40]}$. The TEM images revealed irregular shaped $\mathrm{nHA}$ and $\mathrm{nBG}$ that are illustrated in Figure 9. The SEM image (Fig. 10) of CTS/nBG and CTS/nHA scaffolds showed wellinterconnected, heterogeneous pore microstructures. Stretched pores were generated in the scaffold during lyophilization whose formation might be due to hydrogen-bonding formation between polymer and nanoparticles and parallel ice crystal growth. SEM images of scaffolds revealed interconnected mixed size of pores, mainly ranging from $84-190 \mu \mathrm{m}(\mathrm{CTS} / \mathrm{nBG})$ and $110-160 \mu \mathrm{m}$ (CTS/nHA), which were more relevant for tissue engineering because the pore sizes of bone, muscle, and skin vary from $20-300 \mu \mathrm{m}^{[17]}$. The pore size lower than $300 \mu \mathrm{m}$ contribute to proliferation of osteoblast cell easily through the scaffold ${ }^{[41,42]}$. Larger pores allow direct osteogenesis and high oxygenation, whereas smaller pores favors osteochondrial ossification ${ }^{[10]}$. The porous structure of scaffolds provides space for the intracellular matrix formation. Interconnected pores helps to inflow the nutrients and elution of metabolic waste from scaffolds ${ }^{[43]}$.

According to Archimedes' principle, CTS/nBG
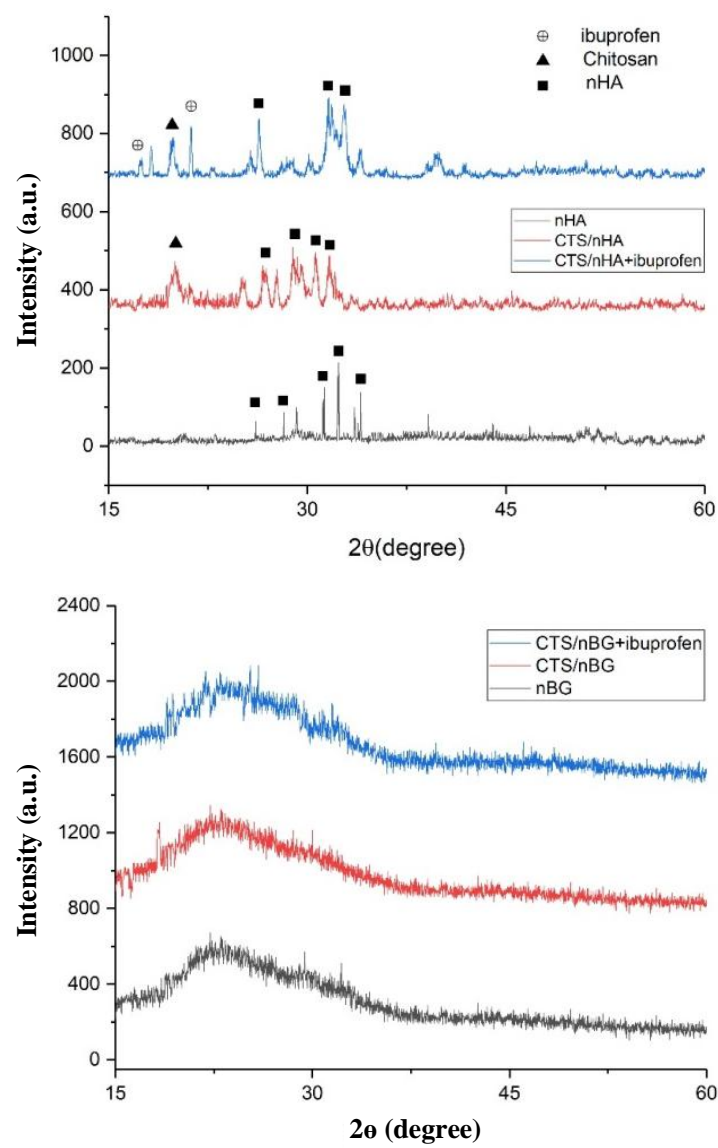

Fig. 8. XRD analysis of (A) nHA, CTS/nHA, and CTS/nHA + ibuprofen samples and (B) XRD analysis of nBG, CTS/nBG, and $\mathrm{CTS} / \mathrm{nBG}+$ ibuprofen samples. 

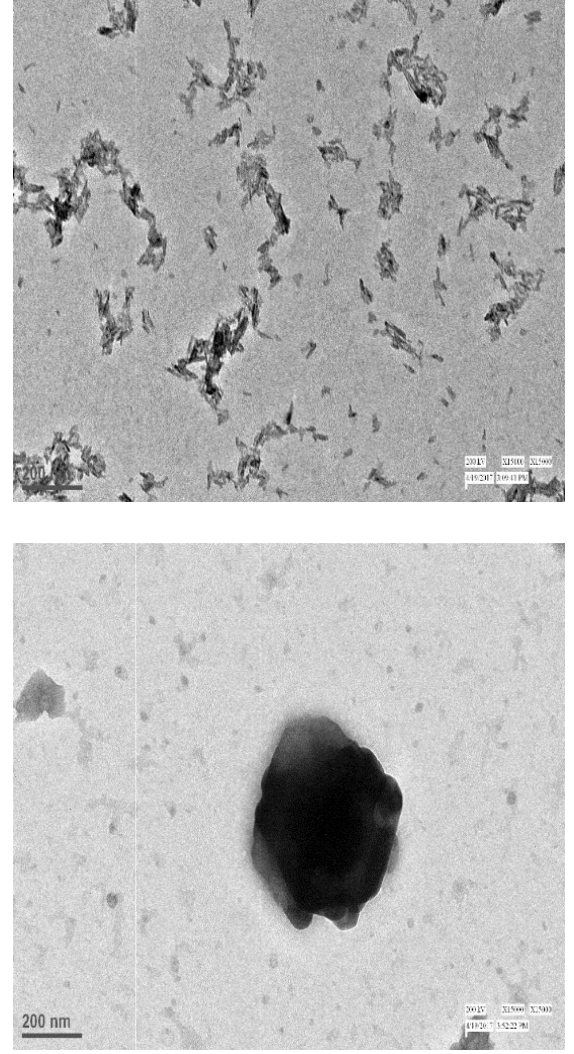

Fig. 9. TEM images of (A) hydroxyapatite and (B) bioglass nanoparticles.

scaffold shows $29 \%$ porosity, while CTS/nBG scaffold indicates $31 \%$ porosity. The surface area and closed porosity of scaffolds were examined by BrunauerEmmett-Teller (BET), as shown in Table 2. The increase in surface area will allow more contact between body fluid and scaffolds. The higher specific area also affects the release kinetics of drug. Many properties like degradation, swelling behavior, nutrients, or mineral exchange depend on the porosity of scaffolds. The scaffold pore size has an impact on both cell migration and diffusion through the scaffold environment.

From BET results, it was observed that drug-loaded CTS/nBG scaffolds offered comparatively more surface area than CTS/nHA scaffolds. The addition of bioglass to CTS leads to the formation of pores with smaller diameter ${ }^{[40]}$. The incorporation of ibuprofen in both samples increased the intermolecular networking with $\mathrm{CTS}^{[30]}$, which may affect the density and porosity of scaffolds. The density of ibuprofen-loaded CTS/nBG $\left(1.9824 \mathrm{~g} / \mathrm{cm}^{3}\right)$ and CTS/nHA (1.9338 $\mathrm{g} / \mathrm{cm}^{3}$ ) scaffolds is better than CTS and CTS /gelatin scaffolds ${ }^{[4]}$ and comparatively more than the normal dry bone $\left(0.8-1.2 \mathrm{~g} / \mathrm{cm}^{3}\right)$ and soft tissues $(1.01-1.06$ $\left.\mathrm{g} / \mathrm{cm}^{3}\right)$. The density of CTS is very low $(0.15-0.30$ $\left.\mathrm{g} / \mathrm{cm}^{3}\right)$ so that bioglass $\left(1-2.6 \mathrm{~g} / \mathrm{cm}^{3}\right)$ and HA $(2-6$ $\mathrm{g} / \mathrm{cm}^{3}$ ) are selected as a dopant for scaffold fabrication. The addition of $\mathrm{nBG}$ and nHA enhanced the density of scaffolds ${ }^{[10,44]}$. The ibuprofen $(10 \% \mathrm{w} / \mathrm{w}$ of CTS) release rate was measured after $24 \mathrm{~h}, 48 \mathrm{~h}$, and $72 \mathrm{~h}$ using UV-Vis spectroscopy. All the readings were compared with the calibrated standard curve of ibuprofen. The ibuprofen release profiles for CTS/nBG and CTS/nHA scaffolds showed a slow release of drug after first $24 \mathrm{~h}$, which may be due to the complex structure of scaffolds ${ }^{[43]}$. The degradation or mineralization behavior of scaffolds may affect the drug release. Drug release approximately 52\% corresponds to CTS/nBG and $46 \%$ corresponds to CTS/nHA scaffold after $72 \mathrm{~h}$. The CTS/nBG scaffold showed slightly fast drug release as compared to CTS/nHA scaffold. Overall, none of scaffold indicated $100 \%$ drug release. The bioglass and HA showed higher absorption, while ibuprofen demonstrated less absorption at $220 \mathrm{~nm}$. Due to high degradation and adsorption capacity of CTS/nBG scaffold, it displayed rapid drug release. The water retention also depends upon porosity or the surface area of scaffolds. The water retention capacity of CTS/nHA scaffold was $34 \%$ that is more than CTS/nBG, CTS, and CTS/gelatin ${ }^{[26]}$ scaffolds. The strong interaction
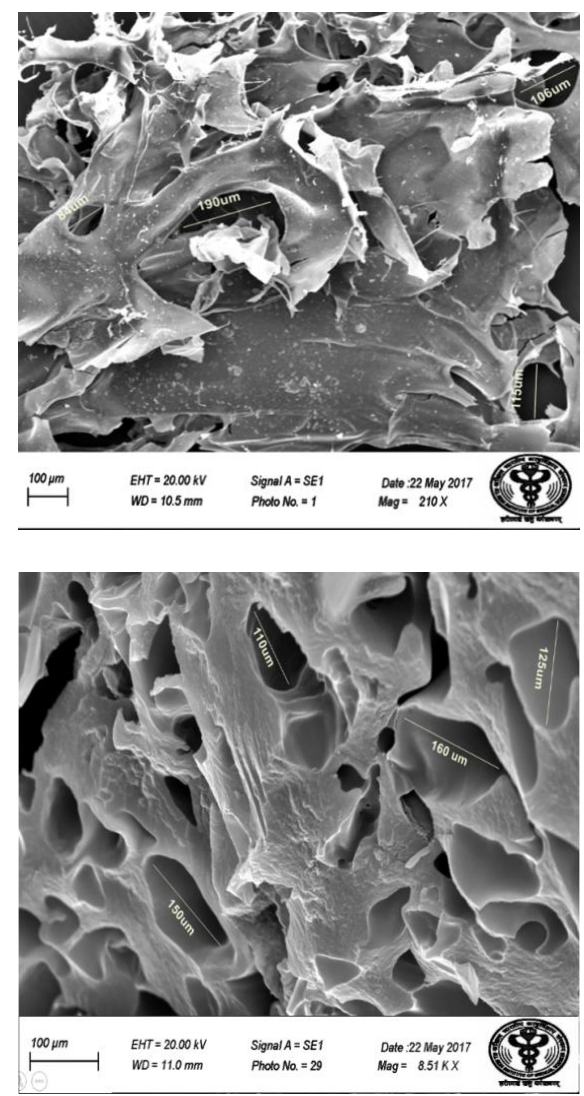

Fig. 10. SEM images of (A) CTS/nHA + ibuprofen scaffold and CTS/nBG + ibuprofen scaffold 

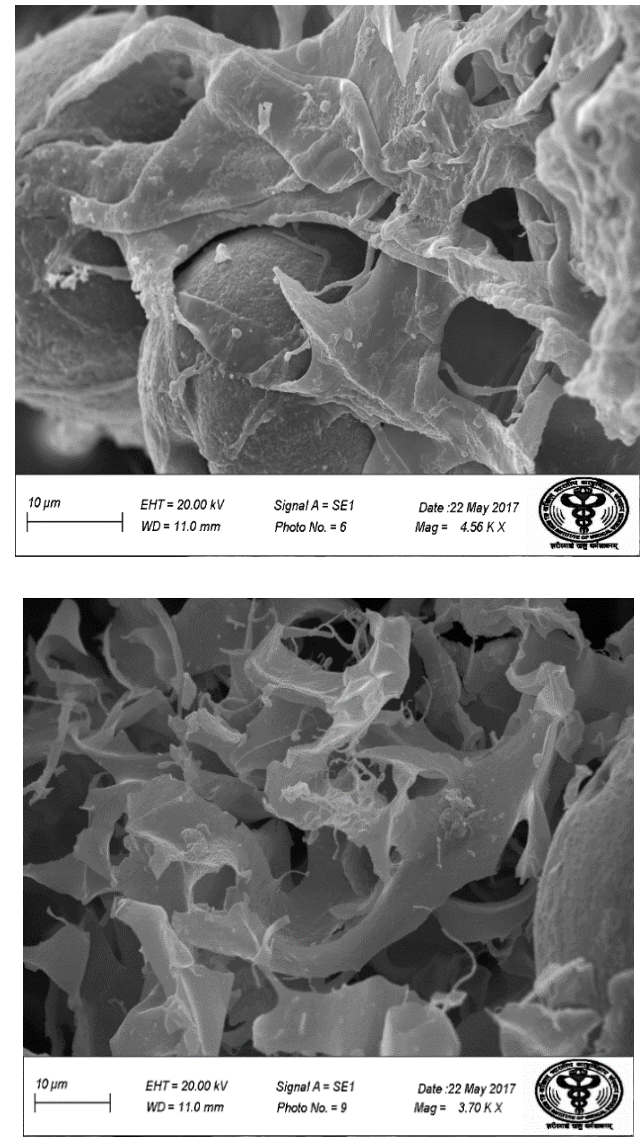

Fig. 11. Mineralization of ibuprofen-loaded CTS/nBG (A) and CTS/nHA (B) scaffolds.

between $\mathrm{nBG}$ and CTS decreases the swelling rate of scaffolds ${ }^{[10]}$. The incorporation of ibuprofen in scaffolds may reduce the water retention capability because ibuprofen is non-polar and insoluble in water. Water retention or swelling behavior of scaffolds helps to fill a specific tissue defect and is helpful for the stable implantation ${ }^{[45]}$. The pre-freezing temperature may affect the physiochemical state of the scaffolds. The in vitro weight degradation of CTS/nHA scaffold was found to be $12.6 \%$ after seven days and $26.1 \%$ after 14 days, while CTS/nBG scaffold was observed to be $14.5 \%$ after seven days and $32.8 \%$ after 14 days of incubation. The degradation rate of CTS/nBG scaffold was slow due to the neutralization of the acidic degradation products of CTS by the alkali groups leaching from bioglass ${ }^{[10,46]}$. The degradation rate of CTS/nHA scaffolds decreased when compared to other scaffolds, which may be due to the high degree crystallinity of nHA. The degree of crystallinity and the nature of polymer may also control the hydrolysis and degradation rate ${ }^{[10]}$. The addition of ibuprofen did not affect the degradation of scaffolds. The regeneration of new tissue needs to replace and degrade the implanted scaffold because the degradation rate plays a crucial role in tissue engineering. The scaffolds were immersed in the beakers containing SBF in an incubator at $37{ }^{\circ} \mathrm{C}$ for seven days to check the bioactivity. SBF provides the same environment as blood plasma where scaffolds show slow release of ions in the solvent. The surface dissolution starts mineralization that generates apatite confirmed by SEM (Fig. 11).

The doping of nHA and $\mathrm{nBG}$ with CTS made effective improvements in the strength of scaffolds. Ibuprofen loading in the scaffolds made small but significant changes in the compressive strength. CTS/nHA scaffold is more brittle than CTS/nBG scaffold. The incorporation of ibuprofen in scaffolds did not show any influence on fibroblast proliferation ${ }^{[47]}$. After pre-selected time intervals (7 and 14 days), the number of cells increased (Fig. 12). The CTS/nHA and CTS/nBG scaffolds support that the differentiation of fibroblast cells is faster than ibuprofen-loaded scaffolds, though fibroblast cells were successfully grown on the surface of ibuprofenloaded scaffolds.

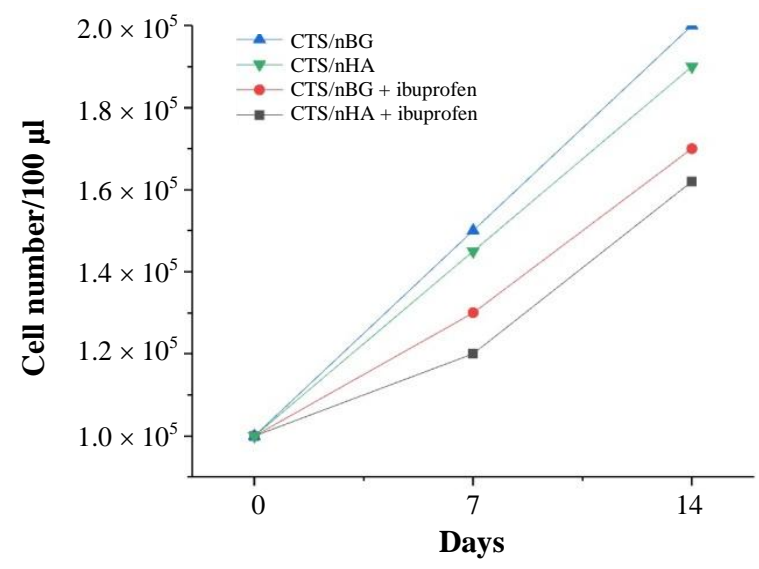

Fig. 12. Cell proliferation on $\mathrm{CTS} / \mathrm{nHA}$ and $\mathrm{CTS} / \mathrm{nBG}$ scaffolds as a function of time.

Table 2. Surface area and porosity measurements of scaffolds

\begin{tabular}{cccccc}
\hline $\begin{array}{c}\text { Surface } \\
\text { no. }\end{array}$ & $\begin{array}{c}\text { Scaffolds } \\
\text { types }\end{array}$ & $\begin{array}{c}\text { Specific surface } \\
\text { area }\left(\mathbf{m}^{\mathbf{2}} \mathbf{g}^{-\mathbf{1}}\right)\end{array}$ & $\begin{array}{c}\text { Pore specific surface } \\
\mathbf{a r e a ~}\left(\mathbf{m}^{\mathbf{2}} \mathbf{g}^{-\mathbf{1}}\right)\end{array}$ & $\begin{array}{c}\text { Pore volume } \\
\left(\mathbf{c m}^{\mathbf{3}} \mathbf{g}^{-\mathbf{1}}\right)\end{array}$ & $\begin{array}{c}\text { Micro pore } \\
\text { diameter }(\mathbf{n m})\end{array}$ \\
\hline 1 & CTS/nBG + ibuprofen & 2.5646 & 1.9986 & 0.0030 & 2.77 \\
2 & CTS/nHA + ibuprofen & 2.7112 & 2.1885 & 0.0052 & 2.54 \\
\hline
\end{tabular}


We successfully fabricated ibuprofen-loaded natural polymer based on scaffolds with improved biomechanical properties. These scaffolds proved their biocompatibility with fibroblast cells without producing cytotoxicity. Doping of nHA and $\mathrm{nBG}$ improved many characteristics of scaffolds such as biocompatibility, biodegradability, swelling, and mechanical behavior etc. The addition of ibuprofen does not affect the cell proliferation activity of scaffolds. The density of both scaffolds meets the parameters of dry bone density. The highly porous structure of scaffolds provides high surface area for cell attachment and nutrient exchange. This structure mimics the functions of the extracellular matrix of bones. The improved mechanical properties of CTS/nHA and CTS/nBG scaffolds will help to create temporary products for tissue engineering. These encouraging results support the potential applications of ibuprofen-loaded CTS/nHA and CTS/nBG scaffolds, as an upgraded substitute, to other natural polymer-based scaffolds for the applications of tissue engineering. The ibuprofen-loaded scaffolds may improve the clinical applications of tissue engineering.

CONFLICT OF INTEREST. None declared.

\section{REFERENCES}

1. Gao C, Peng S, Feng P, Shuai C. Bone biomaterials and interactions with stem cells. Bone research 2017; 5: 17059 .

2. Logeart-Anagnostou D, Anagnostou F, Bizios R, Petite $\mathrm{H}$. Engineering bone: challenges and obstacles. Journal of cellular and molecular medicine 2005; 9(1): 72-84

3. Hutmacher DW. Scaffold design and fabrication technologies for engineering tissues - state of the art and future perspectives. Journal of biomaterials science, polymer editio $2001 ; 12(1): 107-124$.

4. O'Keefe RJ, Mao J. Bone tissue engineering and regeneration: from discovery to the clinic - an overview. Tissue engineering part B: reviews 2011; 17(6): 389-392.

5. Wang C, Shen H, Tian Y, Xie Y, Li A, Ji L, Niu Z, Wu D, Qiu D. Bioactive nanoparticle-gelatin composite scaffold with mMechanical performance comparable to cancellous bones. ACS applied materials and interfaces 2014; 6(15): 13061-13068.

6. Pountos I, Georgouli T, Calori GM, Giannoudis PV. Do nonsteroidal anti-inflammatory drugs affect bone healing? A critical analysis. Scientific world journal 2012; 2012: 606404

7. Chen H, Truckenmüller R, Van Blitterswijk C, Moroni L. Fabrication of nanofibrous scaffolds for tissue engineering applications BT -Nanomaterials in Tissue Engineering [Internet]. In: Woodhead Publishing Series in Biomaterials. Woodhead Publishing; 2013, 158-183.
8. Thein-Han WW, Saikhun J, Pholpramoo C, Misra RDK, Kitiyanant Y. Chitosan-gelatin scaffolds for tissue engineering: Physico-chemical properties and biological response of buffalo embryonic stem cells and transfectant of GFP-buffalo embryonic stem cells. Acta biomaterialia 2009; 5(9): 3453-3466.

9. Di Martino A, Sittinger M, Risbud MV. Chitosan: a versatile biopolymer for orthopaedic tissue-engineering. Biomaterials 2005; 26(30): 5983-5990.

10. Peter M, Binulal NS, Nair S V., Selvamurugan N, Tamura H, Jayakumar R. Novel biodegradable chitosangelatin/nano-bioactive glass ceramic composite scaffolds for alveolar bone tissue engineering. Chemical engineering journal 2010; 158(2): 353-361.

11. Jiang T, M. Pilane C, T. Laurencin C. Fabrication of novel porous chitosan matrices as scaffolds for bone tissue engineering. MRS symposium proceedings 2005; 845: 187-192

12. Yamamoto M, Takahashi Y, Tabata Y. Controlled release by biodegradable hydrogels enhances the ectopic bone formation of bone morphogenetic protein. Biomaterials 2003; 24(24): 4375-4383.

13. Sultana N, Abdul Kadir MR. Study of in vitro degradation of biodegradable polymer based thin films and tissue engineering scaffolds. African journal of biotechnology 2011; 10(81): 18709-18715.

14. Orrego CE, Valencia JS. Preparation and characterization of chitosan membranes by using a combined freeze gelation and mild crosslinking method. Bioprocess biosystems engineering 2009; 32(2): $197-$ 206.

15. Pati F, Kalita H, Adhikari B, Dhara S. Osteoblastic cellular responses on ionically crosslinked chitosantripolyphosphate fibrous 3-D mesh scaffolds. Journal of biomedical materials research part A 2013; 101(9): 2526-2537.

16. Porter JR, Ruckh TT, Popat KC. Bone tissue engineering: A review in bone biomimetics and drug delivery strategies. Biotechnology progress 2009; 25(6): $1539-1560$

17. Kumar P, Dehiya BS, Sindhu A, Yadav A. Physiochemical, morphological and biological characteristics of spherical hydroxyapatite particles. International journal of engineering technology science and research 2017; 4(7): 313-319.

18. Mori K, Hara T, Mizugaki T, Ebitani K, Kaneda K. Hydroxyapatite-supported palladium nanoclusters: a highly active heterogeneous catalyst for selective oxidation of alcohols by use of molecular oxygen. Journal of the American chemical society 2004; 126(34): 10657-10666.

19. $\mathrm{Hu}$ Q, Li B, Wang M, Shen J. Preparation and characterization of biodegradable chitosan/ hydroxyapatite nanocomposite rods via in situ hybridization: a potential material as internal fixation of bone fracture. Biomaterials 2004; 25(5): 779-785.

20. Kokubo T, Takadama H. How useful is SBF in predicting in vivo bone bioactivity? Biomaterials 2006; 27(15): 2907-2915.

21. Earl JS, Wood DJ, Milne SJ. Hydrothermal synthesis of 
hydroxyapatite. Journal of physics 2006; 26(26): 268271.

22. Hong Z, Reis RL, Mano JF. Preparation and in vitro characterization of novel bioactive glass ceramic nanoparticles. Journal of biomedical materials research part A 2009; 88(2): 304-313.

23. D. Bizari, M. Rabiee, F. Moztarzadeh, M. Tahriri, Alavi SH, Masaeli R. Synthesis, characterization and biological evaluation of sol-gel derived nanomaterial in the ternary system $64 \% \mathrm{SiO}_{2}-31 \% \mathrm{CaO}-5 \% \mathrm{P}_{2} \mathrm{O}_{5}$ as a bioactive glass: in vitro study. Ceramics-Silikáty 2008; 57(3): 201-209.

24. Saboori A, Rabiee M, Moztarzadeh F, Sheikhi M, Tahriri M, Karimi M. Synthesis, characterization and in vitro bioactivity of sol-gel-derived $\mathrm{SiO}_{2}-\mathrm{CaO}-\mathrm{P}_{2} \mathrm{O}_{5^{-}}$ $\mathrm{MgO}$ bioglass. Materials science and engineering: $C$ 2009; 29(1): 335-340.

25. Cantón I, Mckean R, Charnley M, Blackwood KA, Fiorica C, Ryan AJ, MacNeil S. Development of an Ibuprofen-releasing biodegradable PLA/PGA electrospun scaffold for tissue regeneration. Biotechnology bioengeering 2010; 105(2): 396-408.

26. Kumar P, Dehiya BS, Sindhu A. Comparative study of chitosan and chitosan-gelatin scaffold for tissue engineering. International nano letters 2017; 7(4): 285290.

27. Kumar P, Dehiya BS and Sindhu A. Bioceramics for hard tissue engineering applications: A review. International journal of applied engineering research 2018; 5(13): 2744-2752.

28. Mao JS, Zhao LG, Yin YJ, Yao K De. Structure and properties of bilayer chitosan-gelatin scaffolds. Biomaterials 2003; 24(6): 1067-1074.

29. Zhang Y, Ni M, Zhang M, Ratner B. Calcium phosphate-chitosan composite scaffolds for bone tissue engineering. Tissue engineering 2003; 9(2): 337-345.

30. Pramanik S, Pingguan-Murphy B, Cho J, Osman NAA. Design and development of potential tissue Engineering scaffolds from structurally different longitudinal parts of a bovine-femur. Scientific reports 2014; 4: 5843.

31. Abioye AO, Issah S, Kola-mustapha AT. Ex vivo skin permeation and retention studies on chitosan-ibuprofengellan ternary nanogel prepared by in situ ionic gelation technique-a tool for controlled transdermal delivery of ibuprofen. International journal of pharmacology 2015; 490(1-2): 112-130.

32. AL-SOU'OD K. Interaction between low molecular weight chitosan and some types of drugs and insulin. Asian journal of chemistry 2012; 24(9): 3785-3790.

33. Vogel $\mathrm{M}$, Voigt $\mathrm{C}$, Gross $\mathrm{UM}, \mathrm{Mu} \mathrm{CM}$. In vivo comparison of bioactive glass particles in rabbits. Biomaterials 2001; 22(4): 357-362

34. Fu Q, Rahaman MN, Bal BS, Brown RF, Day DE. Mechanical and in vitro performance of 13-93 bioactive glass scaffolds prepared by a polymer foam replication technique. Acta biomaterials 2008; 4(6): 1854-1864.

35. Fu Q, Rahaman MN, Fu H, Liu X. Silicate, borosilicate, and borate bioactive glass scaffolds with controllable degradation rate for bone tissue engineering applications. I. Preparation and in vitro degradation. Journal of biomedical materials research part A 2010; 95(1): 164-171.

36. Vitale-Brovarone C, Baino F, Verné E. High strength bioactive glass-ceramic scaffolds for bone regeneration. Journal of materials science: materials in medicine 2009; 20(2): 643-653.

37. Goodridge RD, Wood DJ, Ohtsuki C, Dalgarno KW. Biological evaluation of an apatite-mullite glass-ceramic produced via selective laser sintering. Acta biomaterialia 2007; 3(2): 221-231.

38. Tomihata K, Ikada Y. In vitro and in tivo degradation of films of chitin and its deacetylated derivatives. Biomaterials 1997; 18(7): 567-575.

39. Peluso G, Petillo O, Ranieri M, Ambrosia L, Calabro D, Avallone B, Balsamos G. Chitosan-mediated stimulation of macrophage function. Biomaterials 1994; 15(15): 1215-1220.

40. Mori T, Okumura M, Matsuurat M, Uenos K, Tokura S, Okamoto Y, Minam S, Fujinaga T. Effects of chitin and its derivatives on the proliferation and cytokine production of fibroblasts in vitro. Biomaterials 1997; 18(13): 947-951.

41. Nerantzaki MC, Koliakou IG, Kaloyianni MG, Terzopoulou ZN, Siska EK, Karakassides MA, Boccaccini AR, Bikiaris DN. New N-(2carboxybenzyl)chitosan composite scaffolds containing nanoTiO2or bioactive glass with enhanced cell proliferation for bone-tissue engineering applications. International journal of polymeric materials and polymeric biomaterials 2017; 66(2): 71-81.

42. Karageorgiou V, Kaplan D. Porosity of 3D biomaterial scaffolds and osteogenesis. Biomaterials 2005; 26(27): 5474-5491.

43. Liu H, Zhang L, Shi P, Zou Q, Zou Y, Li Y. Hydroxyapatite/polyurethane scaffold incorporated with drug-loaded ethyl cellulose microspheres for bone regeneration. Journal of biomedical materials research part B 2010; 95(1): 36-46.

44. Kavya KC, Jayakumar R, Nair S, Chennazhi KP. Fabrication and characterization of chitosan/gelatin/ $\mathrm{nSiO} 2$ composite scaffold for bone tissue engineering. International journal of biological macromolecules 2013; 59: 255-263.

45. Jaklenec A, Hinckfuss A, Bilgen B, Ciombor DM, Aaron R, Mathiowitz E. Sequential release of bioactive IGF-I and TGF- b 1 from PLGA microsphere-based scaffolds. Biomaterials 2008; 29(10): 1518-1525.

46. Silver IA, Deas J, Erecinska M. Interactions of bioactive glasses with osteoblasts in vitro: effects of 45S5 Bioglass $®$, and $58 \mathrm{~S}$ and $77 \mathrm{~S}$ bioactive glasses on metabolism, intracellular ion concentrations and cell viability. Biomaterials 2001; 22(2): 175-185.

47. Beata R, Wojciech F, Stanislaw S, Ryszard M. The influence of anti-inflammatory drugs on the proliferation of fibroblast derived from nasal polyps. Auris nasus larynx 2005; 32(2): 225-259. 